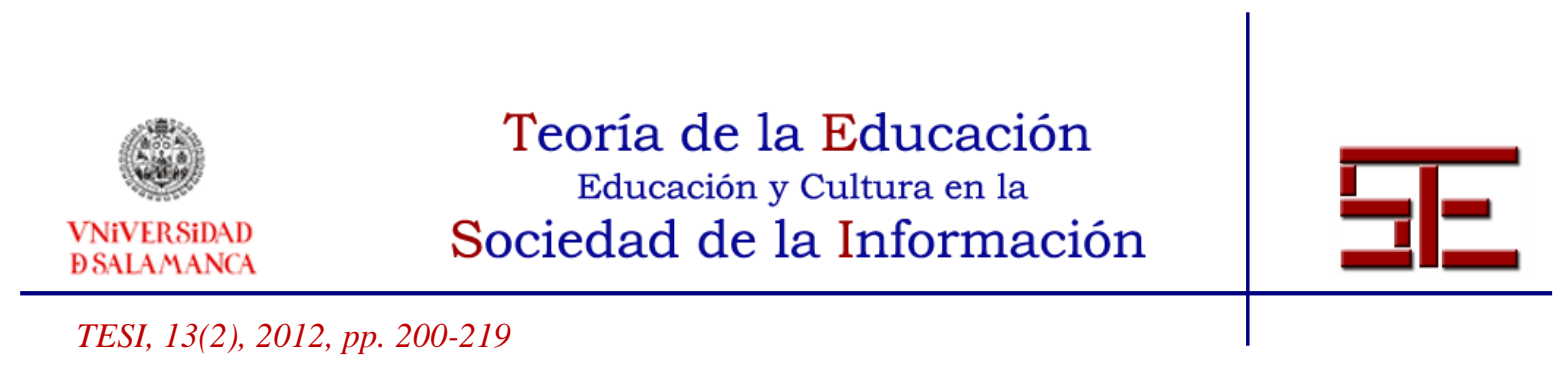

\title{
LA RIQUEZA DE LAS REDES EN LA EDUCACIÓN UNIVERSITARIA: "TRADUCCIÓN ENTRE IGUALES BASADA EN EL PROCOMÚN" DE THE WEALTH OF NETWORKS ${ }^{1}$
}

Resumen: Una de las competencias transversales en las que más insisten las últimas reformas universitarias es el trabajo cooperativo, la cual experimenta un paulatino asentamiento en las aulas universitarias (sean sus muros físicos o virtuales). Ello es fruto de una dilatada investigación psicológica y pedagógica, a la que se ha sumado la más reciente sobre los usos educativos de las tecnologías de la información y la comunicación (TIC). Ahora bien, el actual desarrollo del aprendizaje cooperativo en la educación superior supone un reflejo del protagonismo cada vez mayor de la cooperación en la investigación académica y en nuestra propia experiencia cotidiana vinculada a las redes de comunicación informáticas.

El proyecto de traducción de la obra de Yochai Benkler The Wealth of Networks que se presenta en estas líneas se ubica en la intersección ambivalente de estas dos tendencias con el propósito de explorar la afluencia de esa "riqueza de las redes" a la educación superior, imbricando la dimensión educativa con la de producción social de conocimiento. En este sentido, el principal objetivo de la presente reflexión es contribuir a la discusión sobre procesos de enseñanza/aprendizaje que, tanto en su metodología como en sus contenidos, permitan vincular coherentemente las tareas académicas (tanto docentes como investigadoras) con exitosas formas de cooperación social herederas del movimiento de software libre e inspiradas por la fértil reivindicación de un procomún en el ámbito comunicativo.

Palabras clave: Aprendizaje cooperativo; docencia universitaria; Tecnologías de la Información y la Comunicación (TIC); producción entre iguales basada en el procomún.

${ }^{1}$ Este proyecto ha contado con apoyo y financiación del Laboratorio del Procomún de Medialab-Prado (Madrid) y del Servicio de Innovación Educativa de la Universidad de Málaga.

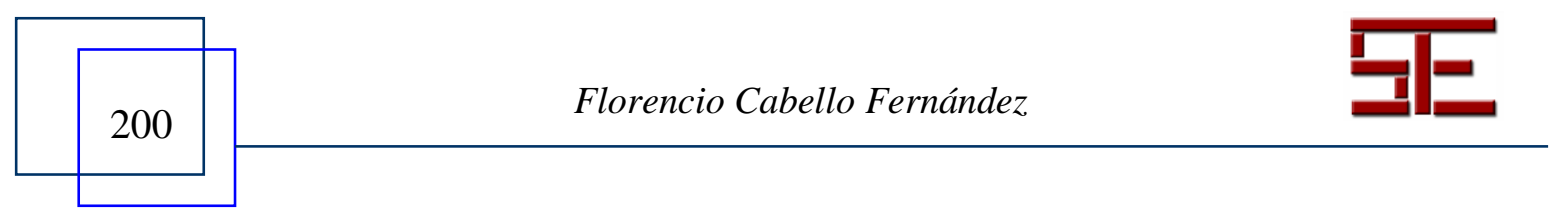




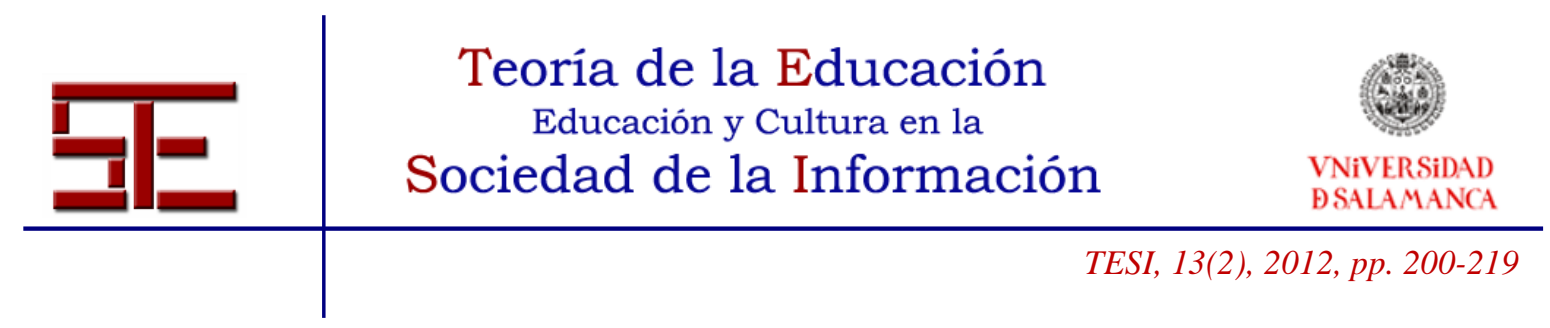

\title{
THE WEALTH OF NETWORKS IN UNIVERSITY TEACHING: "COMMONS- BASED PEER TRANSLATION” OF THE WEALTH OF NETWORKS
}

\begin{abstract}
Cooperative work is one of the most significant competencies in recent University reforms, and is achieving a gradual introduction in university classrooms (may their walls be physical or virtual). This results from extensive psychological and pedagogical research, together with more recent studies on educational uses of Information and Communication Technologies (ICTs). Nevertheless, the current development of cooperative learning in higher education entails a reflection of the evergrowing prominence of cooperation in academic research as well as in everyday life in our networked environment.
\end{abstract}

The translation project of Yochai Benkler's The Wealth of Networks presented here sits at the ambivalent intersection between these two trends in order to explore the influx of that "wealth of networks" into higher education, bringing together both educational and social production dimensions. In this sense, the main goal of this exposition is to contribute to the debate on teaching/learning processes that, both through methodology and content, enable to link consistently teaching and research work with successful patterns of social cooperation inspired by the free software movement and the fruitful claim for a communication commons.

Keywords: Cooperative learning; university teaching; Information and Communication Technologies (ICTs); commons-based peer production.

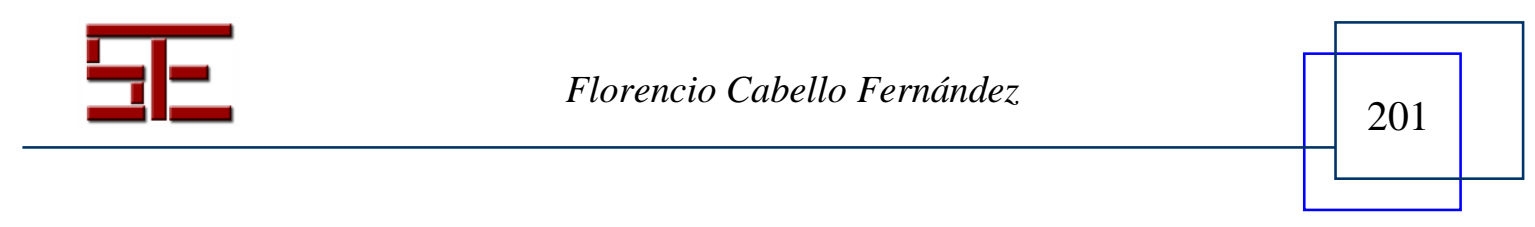




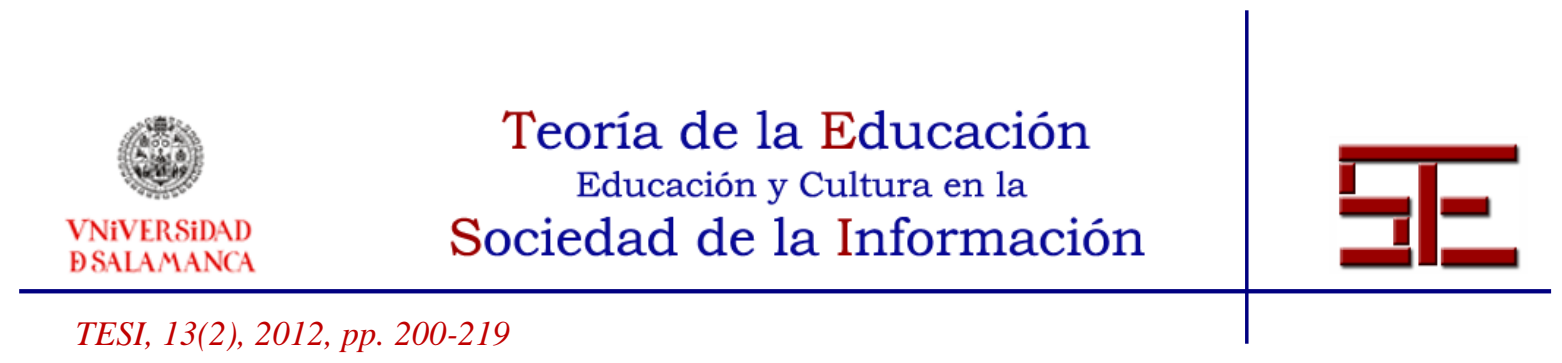

\section{LA RIQUEZA DE LAS REDES EN LA EDUCACIÓN UNIVERSITARIA: "TRADUCCIÓN ENTRE IGUALES BASADA EN EL PROCOMÚN" DE THE WEALTH OF NETWORKS}

Fecha de recepción: 15/02/2011; fecha de aceptación: 2/06/2012; fecha de publicación: 26/07/2012

Florencio Cabello Fernández

fcabello@uma.es

Universidad de Málaga

\section{INTRODUCCIÓN}

Una de las competencias transversales en las que más insisten las últimas reformas universitarias es el trabajo cooperativo, la cual experimenta un paulatino asentamiento en las aulas universitarias (sean sus muros físicos o virtuales). Ello es fruto de una dilatada investigación psicológica y pedagógica, a la que se ha sumado la más reciente sobre los usos educativos de las tecnologías de la información y la comunicación (TIC). Ahora bien, el actual desarrollo del aprendizaje cooperativo en la educación superior supone un reflejo del protagonismo cada vez mayor de la cooperación en la investigación académica y en nuestra propia experiencia cotidiana vinculada a las redes de comunicación informáticas.

Afirmar lo anterior no implica en absoluto proclamar el triunfo de la cooperación frente al darwinismo social y la expansión neoliberal. No obstante, el creciente protagonismo de la cooperación, propiciado por unas condiciones tecnológicas singularmente favorables, evidencia los olvidos de algunas escuelas de investigación. A ello alude Yochai Benkler (2006; 116-117) cuando, centrándose en el análisis económico de las emergentes formas de producción social, señala la "curiosa congruencia" entre la antropología del don y la teoría económica hegemónica, al subrayar ambas su carácter periférico y arcaico, a lo que respone:

La producción social no se circunscribe a bienes públicos, a emplazamientos exóticos y remotos [...], ni siquiera al fenómeno ubicuo de las tareas domésticas. [N]o se limita necesariamente a comunidades estables de individuos que interactúan a menudo y se conocen mutuamente, o que esperan seguir interactuando personalmente. La producción social de bienes y servicios, tanto públicos como privados, es ubicua, aunque pase desapercibida, y unas veces sustituye y otras

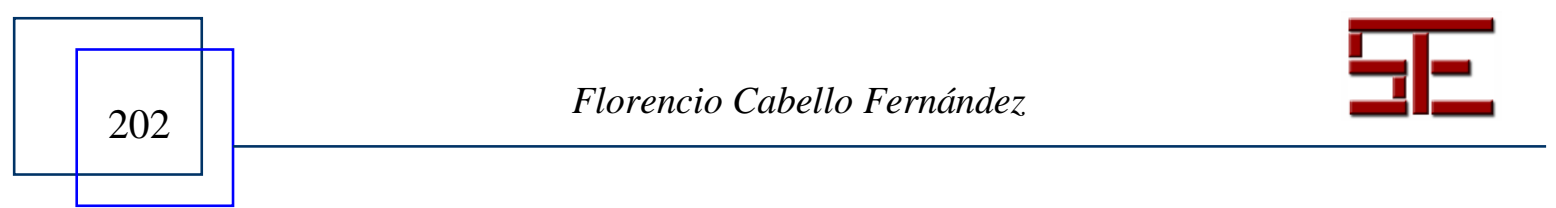




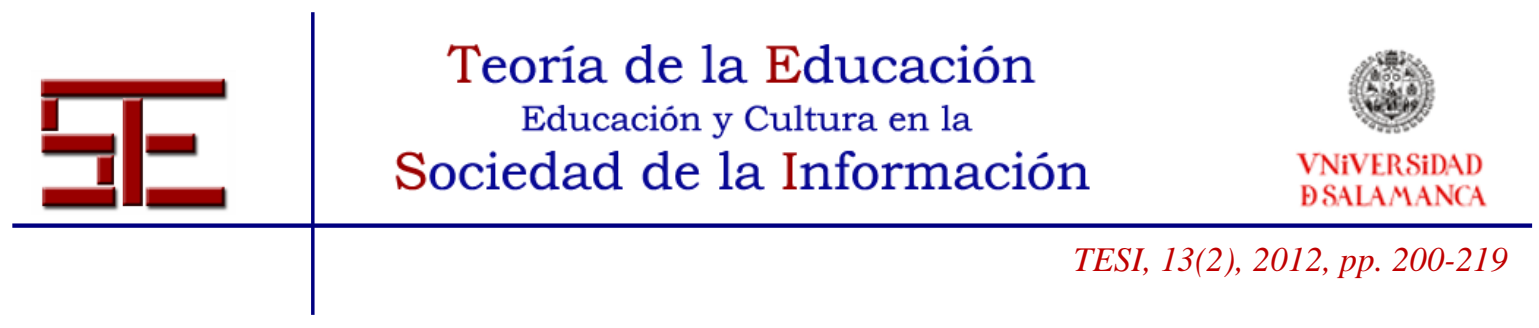

complementa la producción mercantil y estatal. Por expresarlo de modo extravagante, se trata de la materia oscura de nuestro universo de producción económica.

El proyecto de traducción de la obra de Yochai Benkler The Wealth of Networks que se presenta en estas líneas se ubica en la intersección ambivalente de estas dos tendencias con el propósito de explorar la afluencia de esa "riqueza de las redes" a la educación superior, imbricando la dimensión educativa con la de producción social de conocimiento. En este sentido, el principal objetivo de la presente reflexión es contribuir a la discusión sobre procesos de enseñanza/aprendizaje que, tanto en su metodología como en sus contenidos, permitan vincular coherentemente las tareas académicas (tanto docentes como investigadoras) con exitosas formas de cooperación social herederas del movimiento de software libre e inspiradas por la fértil reivindicación de un procomún en el ámbito comunicativo.

En efecto, el origen de este proyecto vincula la cuestiones planteadas arriba con la tarea emprendida en 2008 de reformular la materia Tecnología de la Comunicación Audiovisual, impartida por Florencio Cabello en la Facultad de Ciencias de la Comunicación de la Universidad de Málaga (UMA). La voluntad de enfocar una materia escasamente actualizada hacia la digitalización y la convergencia tecnológica y hacia la preeminencia de las redes de comunicación informática sugería proponer como obra de referencia un clásico en el campo de las TIC e Internet: El Código y otras leyes del ciberespacio, de Lawrence Lessig, fundador de Creative Commons (CC) (Cabello, 2004).

Ahora bien, por más que esa obra estuviera disponible en castellano merced a la edición de Taurus, en 2006 había aparecido Code 2.0, una actualización que su autor había realizado tras promover entre estudiantes y curiosos un proceso cooperativo de revisión de la misma a través de un wiki. La opción clara de recurrir a esta última versión implicaba plantearse quién podía encargarse de preparar la traducción que facilitase la lectura y discusión a los estudiantes. En condiciones normales, la respuesta habría sido obvia, pero el proceso de elaboración de Code 2.0 no era precisamente normal. Más aún: era realmente inspirador, incluida su publicación con una licencia $\mathrm{CC}$ que invitaba a copiar y transformar la obra con cualquier propósito, incluido el comercial. De este modo, en febrero de 2008 los estudiantes de Tecnología de la Comunicación Audiovisual fueron invitados por el docente de la materia a emular ese proceso y suministrar al resto de compañeros (y a las promociones venideras) el material didáctico que emplearíamos en clases.

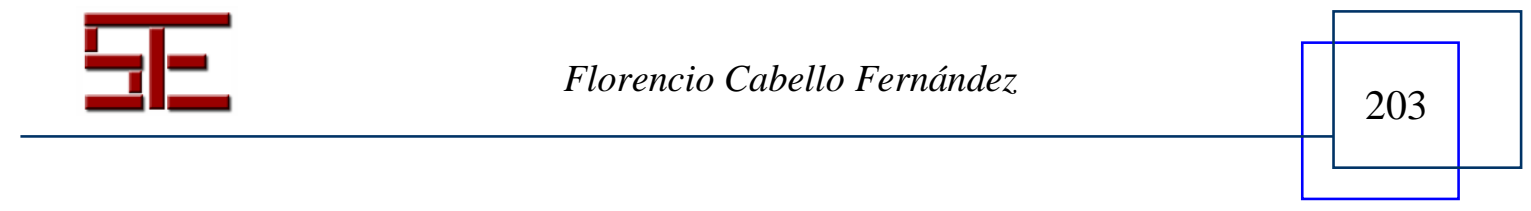




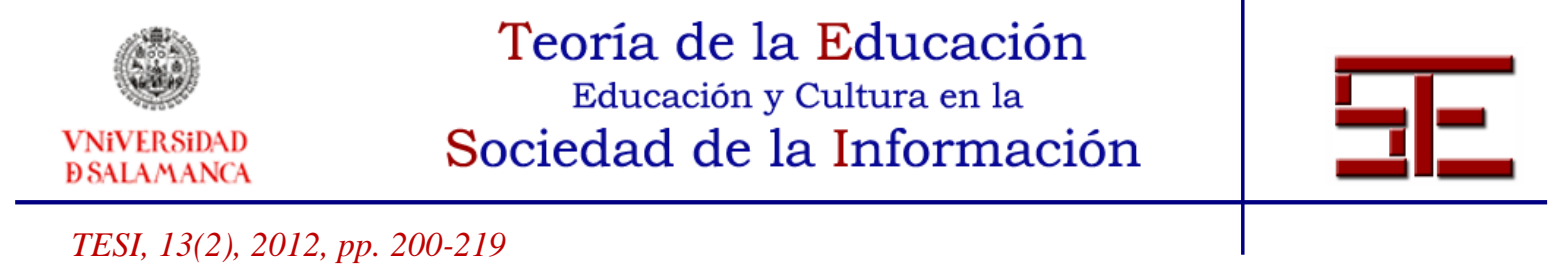

El notable éxito de esta primera iniciativa de cooperación entre estudiantes (finalmente cuarenta y cuatro de un total de ciento treinta) (Cabello, 2009) impulsó su prolongación al comienzo del curso 2008/2009 en dos sentidos: uno primero, dedicado a repetir la experiencia previa con Remix, obra de Lessig (2012) que aborda las prácticas sociales de compartición y remezcla de obras creativas a través de las TIC e Internet como una fuente de oportunidades culturales y comerciales en el marco de lo que denomina "la economía híbrida"; y uno segundo, orientado a que los estudiantes divulgaran su experiencia en distintos foros, lo cual, unido a la ulterior publicación libre de las traducciones (Lessig, 2009, 2012), permite contemplar la dimensión plenamente productiva de su trabajo más allá de los límites del aula (de nuevo, física o virtual).

Fue precisamente el empeño de los estudiantes por difundir su trabajo lo que propició la conexión en el Hackmeeting-2008 con Antonio Lafuente, Marcos García y Laura Fernández, tres de los artífices del Laboratorio del Procomún (LdP) de Madrid. Nacido en 2007, el LdP es un proyecto que se enmarca en las actividades del Medialab-Prado, un espacio del Área de las Artes del Ayuntamiento de Madrid orientado a la producción, investigación y difusión de la cultura digital con una clara vocación participativa. El objetivo del LdP es articular un discurso y una serie de proyectos en torno al concepto de procomún (que defino a continuación), y para ello reúne a investigadores, académicos o no, vinculados a la filosofía, el arte, la ecología, la antropología, la comunicación o el hacking. Fruto de ese encuentro, los miembros del LdP ofrecieron su colaboración para emprender un trabajo conjunto en torno a una obra imprescindible acerca de las mediaciones sociales de las TIC y las redes de comunicación y de sus desafíos políticos, económicos y culturales: The Wealth of Networks, del profesor de Derecho de Harvard Yochai Benkler.

\section{FOCO DE ESTUDIO}

Así pues, en octubre de 2009 se presentó al LdP un proyecto que se abría a incorporar colaboradores de otros ámbitos intelectuales y geográficos al equipo original de la UMA con el fin de emprender la traducción de The Wealth of Networks. Publicada originalmente en 2006, y galardonada con premios en las áreas de Ciencias Políticas, Sociología o Comunicación, esta obra parte de un análisis exhaustivo de las transformaciones tecnológicas y económicas que definen la transición hacia una "economía de la información en red". A continuación, aborda críticamente sus implicaciones comunicativas y culturales en el marco de otra transición fundamental hacia una "esfera pública en red", una cultura "crítica y plástica" y nuevas formas de

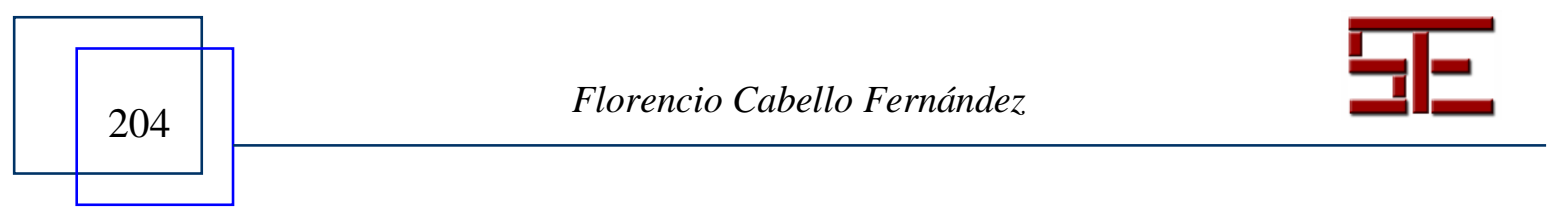




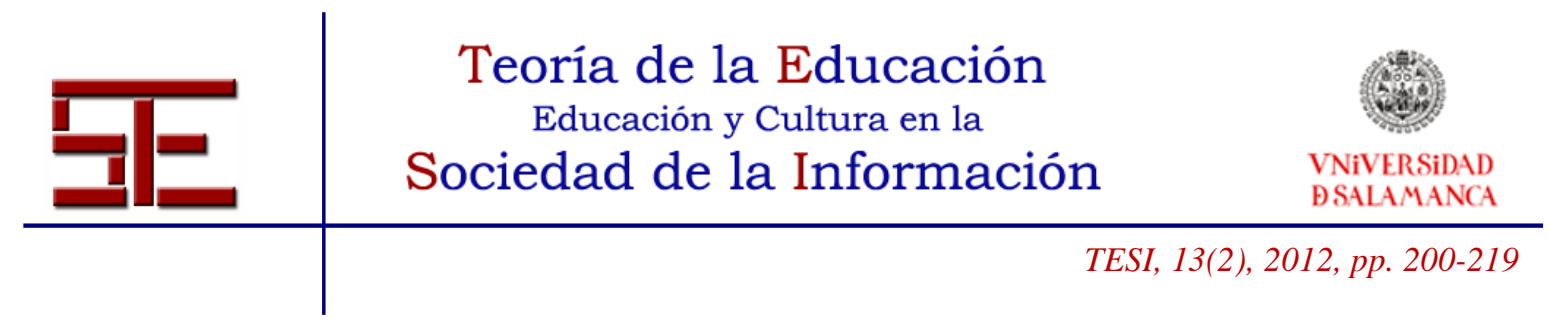

socialidad. Finalmente, este amplio espectro de consideraciones confluye en unas conclusiones que ofrecen un mapa sobre los principales retos relacionados con el alcance y sostenibilidad de la producción social, la "batalla en torno a la ecología institucional del entorno digital" y la construcción de un procomún en el ámbito comunicativo.

Dentro de este esquema general de la obra, nuestra atención se orienta hacia esa "riqueza de las redes" vinculada a las TIC, las redes de comunicación informática y el procomún. Más concretamente, identificamos nuestro foco de estudio con la multiplicidad de prácticas sociales propiciadas por el entorno comunicativo en red que Benkler (op. cit. 60) engloba en su definición de la "producción entre iguales basada en el procomún": "Una nueva modalidad de organización productiva radicalmente descentralizada, cooperativa y no privativa; basada en recursos y productos compartidos entre individuos extensamente distribuidos y difusamente conectados que cooperan sin depender de directrices mercantiles o de órdenes jerárquicas”.

Abundando en esta definición de nuestro foco de estudio, considero imprescindible precisar el significado del concepto central de "procomún", viejo vocablo castellano rescatado por el LdP como propuesta de traducción de "commons" (literalmente, terrenos o bienes comunales). Para empezar, una referencia inexcusable es Elinor Ostrom, Premio Nobel de Economía de 2009 por su investigación sobre el éxito de estrategias comunales de gestión de recursos (eminentemente naturales, pero también informativos o culturales) que prescinden del Estado y de los mercados. Pues bien, Hess y Ostrom (2007; 3-5) definen el procomún como:

...un recurso compartido por un grupo de personas que está sujeto a dilemas sociales. [El recurso] puede ser pequeño y servir a un grupo minúsculo (el frigorífico de la familia), puede ser comunitario (aceras, parques de recreo, bibliotecas y demás), o puede extenderse a escala internacional o mundial (los fondos marinos, la atmósfera, Internet o el conocimiento científico). El procomún puede estar bien delimitado (un parque o una biblioteca comunitarios); ser transfronterizo (el río Danubio, las especies migratorias, Internet); o carecer de límites claros (el conocimiento, la capa de ozono).

Partiendo de este trabajo, Benkler (op. cit. 60-61) define el procomún como "una específica forma institucional de estructurar el derecho de acceso, uso y control de los recursos". Se opone a la propiedad en el sentido de que, en lugar de asignar a un propietario el control exclusivo de los recursos, establece que "cualquier miembro de un grupo (más o menos definido) de personas puede usar o disponer de los recursos regidos

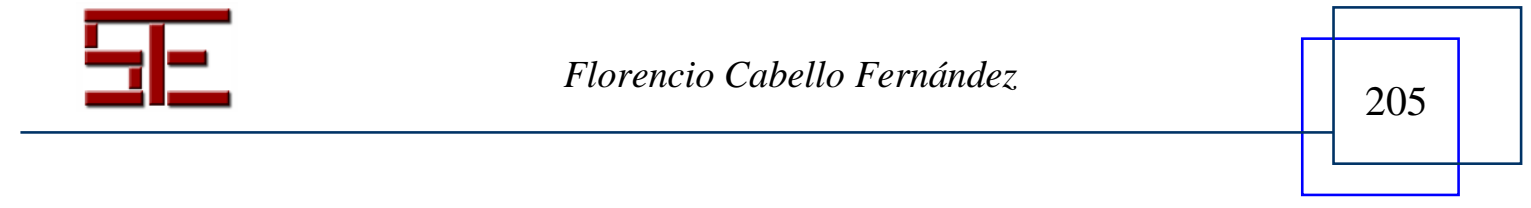




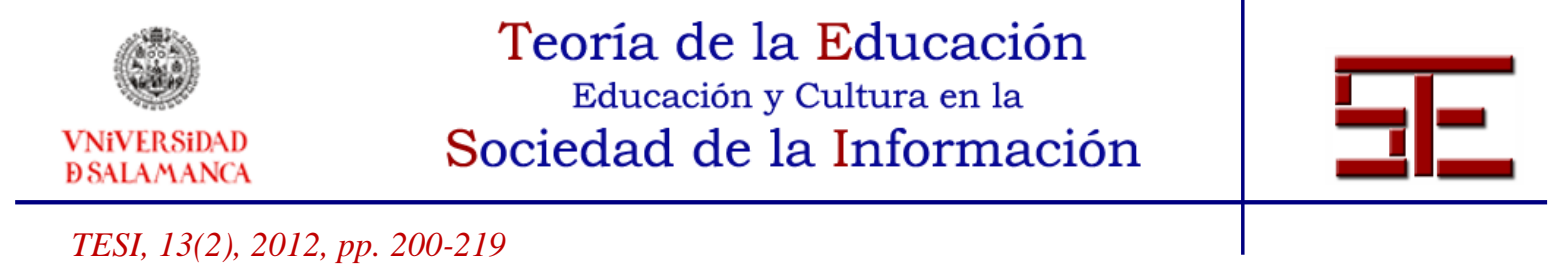

por el procomún, de acuerdo con unas normas que pueden ir desde el "todo vale" a reglas formales escrupulosamente articuladas que se aplican de modo efectivo". En este sentido, el autor distingue cuatro tipos de procomún en función de si el acceso es abierto o restringido a un grupo concreto, y de si está regulado o no.

En síntesis, Benkler (ibid. 62) puntualiza que la expresión "basada en el procomún" alude a que "la característica de las empresas cooperativas que describo [es que] los insumos y productos del proceso son compartidos, de manera libre o condicional, en un marco institucional que los hace igualmente disponibles para que todos los usen a discreción". Por su parte, la expresión "producción entre iguales" abarca "un subconjunto de prácticas productivas basadas en el procomún [...] que dependen de una acción individual autodeterminada y descentralizada, y no asignada jerárquicamente”.

Junto a esta definición de la "producción entre iguales basada en el procomún", Benkler (ibid. 99-106) apunta valiosas pistas sobre sus criterios de sostenibilidad y formas organizativas. De este modo, el autor identifica tres rasgos que posibilitan la viabilidad de una experiencia de producción social, rasgos que en el próximo apartado aplicaremos a nuestro proyecto de traducción de esta misma obra.

Los dos primeros consisten en la disponibilidad de la "maquinaría física" (dispositivos informáticos) y de "las materias primas fundamentales de la economía de la información [...] - la información, el conocimiento y la cultura existentes - , cuyo coste marginal real es cero" (ibid. 114). Ahora bien, el éxito de la producción entre iguales basada en el procomún depende de un tercer rasgo que permite aprovechar los dos anteriores: la adopción de arquitecturas técnicas y organizativas que faculten el acopio e integración de contribuciones que, como en nuestro proyecto, son "muy diversas por lo que respecta a su calidad, cantidad y enfoque, así como en su ubicación temporal y geográfica" (ibid. 108).

Antes de examinar las características fundamentales de dichas arquitecturas, estimo oportuno subrayar la concepción tecnológica que subyace a este tercer rasgo, la cual es heredera de la investigación sobre las "propiedades políticas" de la tecnología (Winner, 2008) y de la defensa de Lessig (2009) de la decisiva influencia de los principios imbuidos en el diseño tecnológico del ciberespacio para su configuración política, sintetizada en su lema "El código es la ley". En efecto, Benkler descarta el determinismo tecnológico sin por ello incurrir en el reduccionismo de considerar las

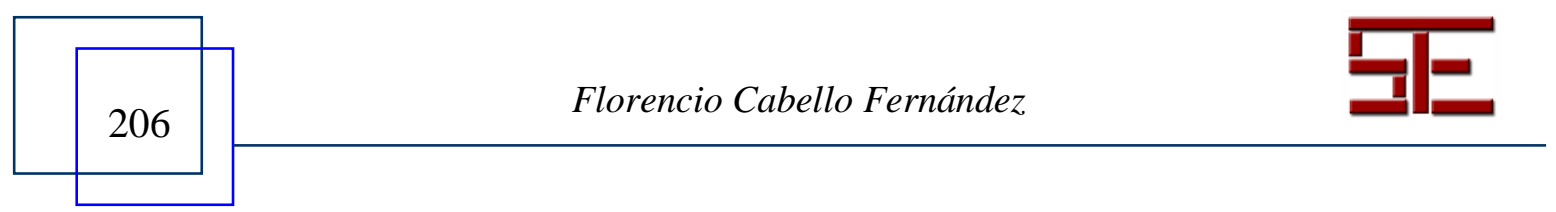




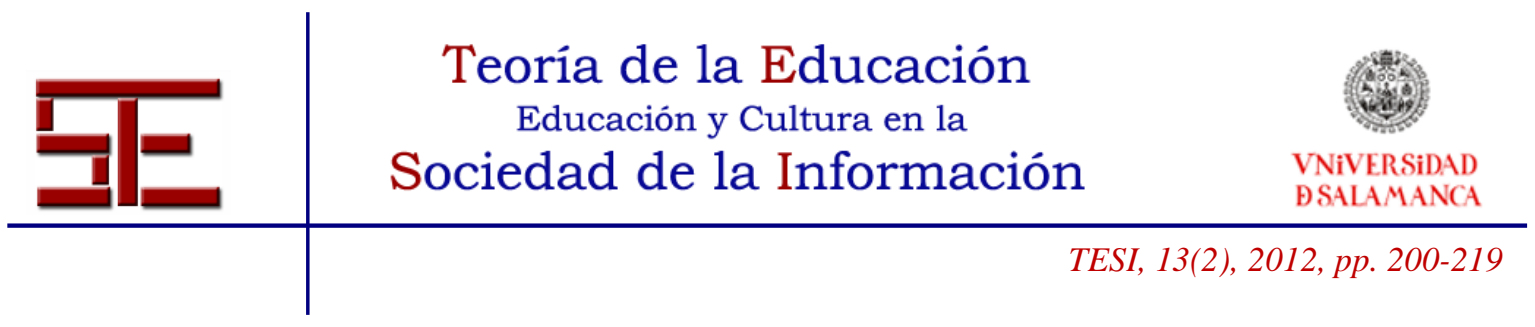

TIC como meros instrumentos cuyas pautas de uso responden exclusivamente a lo que disponga cada sociedad y cultura:

Sin ser ni determinista ni completamente maleable, la tecnología establece algunos parámetros para la acción individual y social. Puede facilitar algunas acciones, relaciones, organizaciones e instituciones, y dificultar otras. [...] Con todo, dentro del ámbito de lo factible — esto es, de los usos no imposibilitados por la adopción o rechazo de una tecnología-, las diferentes pautas de adopción y uso pueden dar como resultado que en torno a la tecnología surjan relaciones sociales muy diferentes (Benkler, op. Cit. 17-18).

Apuntado esto, las características fundamentales que propician la viabilidad de este tipo de proyectos son la modularidad y la capacidad de aglutinar contribuciones de grano fino. Benkler define la primera como "aquella propiedad de un proyecto que describe la medida en que este puede descomponerse en componentes más pequeños, o módulos, que es posible producir independientemente antes de ensamblarlos en un conjunto" (ibid. 100). La clave reside en que la independencia de los módulos se traduce en autonomía y flexibilidad para que múltiples colaboradores pueden trabajar separadamente como mejor convenga a su implicación, disponibilidad y horario.

En esta organización por módulos resulta crucial la característica de la "granularidad", que "se refiere al tamaño de los módulos, en términos de tiempo y esfuerzo que un individuo debe invertir para producirlos" (idem). Así, cuanto más reducida sea esa inversión individual mínima para colaborar en un proyecto (cuanto más fina sea su granularidad), mayor será el universo de potenciales participantes y menor será la necesidad de ofrecerles incentivos significativos.

\section{METODOLOGÍA}

Teniendo en cuenta el propósito y el foco de estudio descritos, el diseño metodológico de lo que podríamos denominar "traducción entre iguales basada en el procomún" se apoya en dos referentes fundamentales, que corresponden a la doble dimensión mencionada: el aprendizaje cooperativo y la producción entre iguales basada en el procomún.

\subsection{Aprendizaje cooperativo}

El aprendizaje cooperativo, ampliamente conocido, se basa en la colaboración de alumnos comprometidos individualmente para alcanzar objetivos compartidos

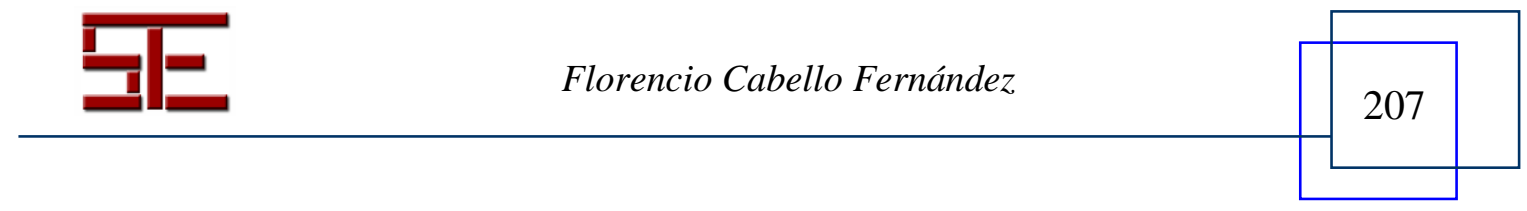




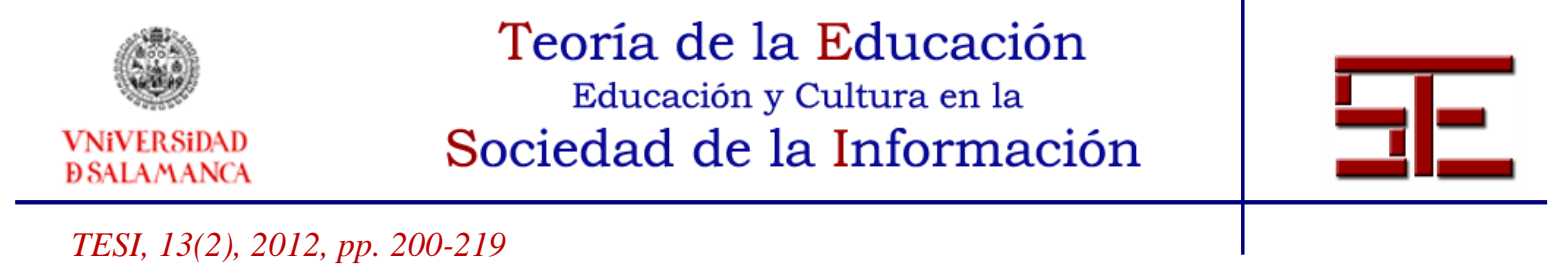

imposibles de lograr de forma individual o competitiva, y es definido por Johnson y Johnson (1999: 20) como "el uso en la educación de grupos pequeños en los que los alumnos trabajan juntos para mejorar su propio aprendizaje y el de los demás". Junto a ello, estos autores distinguen tres tipos de aprendizaje cooperativo, el formal, el informal y los grupos cooperativos de base, siendo la definición de estos últimos la que mejor encaja con nuestro equipo de trabajo: "grupos de aprendizaje cooperativo heterogéneos a largo plazo con miembros estables cuyas responsabilidades primordiales son brindar apoyo, estímulo y ayuda para completar las tareas y responsabilizarse por aprender" (ibid. 104).

En efecto, si la composición del grupo de la UMA ya obligaba a replantearse la adecuación del término "alumno", pues desde el proyecto de Remix la mayoría de voluntarios ya había superado la materia Tecnología de la Comunicación Audiovisual, la inclusión del proyecto en el LdP suponía abrir la convocatoria de colaboradores a una radical heterogeneidad. Esta venía determinada por la dispersión geográfica de los voluntarios, pero también por su diversa procedencia intelectual y profesional, que aconsejaba afinar la hibridación de las distintas motivaciones y actitudes hacia la tarea.

Partiendo de dicha heterogeneidad, a principios de 2010 se conformó un grupo estable de dieciséis personas que durante el resto del año acometerían la traducción observando los cuatro componentes esenciales de las iniciativas cooperativas eficaces que distinguen Johnson y Johnson (ibid. 115-132):

a) La interdependencia positiva de objetivos, que "se da cuando se establece un objetivo mutuo o conjunto de manera tal que los individuos perciben que solo si sus compañeros alcanzan sus objetivos podrán ellos mismos alcanzar los propios" (ibid. 53). Gracias a la experiencia previa con los estudiantes de la UMA, y a que todas las incorporaciones conocían la obra de Benkler y deseaban trabajar en ella, la definición de la tarea se realizó con plenas claridad y complicidad.

b) La interacción promotora cara a cara. Aquí radica la principal diferencia de nuestra metodología con las pautas de Johnson y Johnson. Dicha diferencia no deriva tanto de una discrepancia con respecto a la profunda importancia de la interacción cara a cara cuanto de la pura necesidad de redefinir su papel y de encontrar sucedáneos que permitan paliar su ausencia al tiempo que se aprovecha al máximo el potencial de cooperación de esos "individuos extensamente distribuidos y difusamente conectados" a que aludía Benkler.

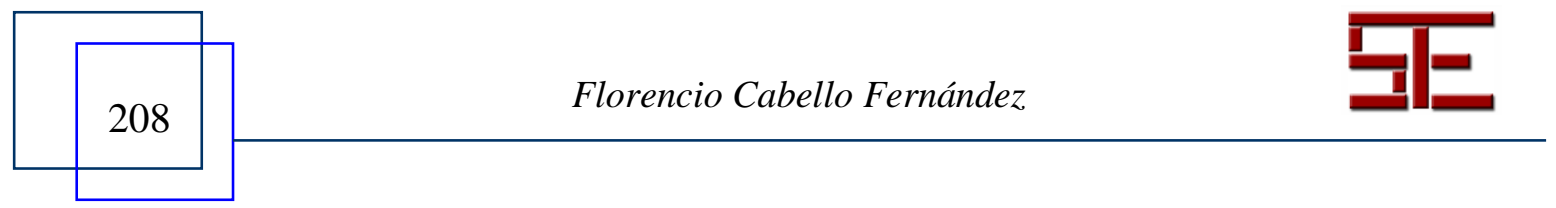




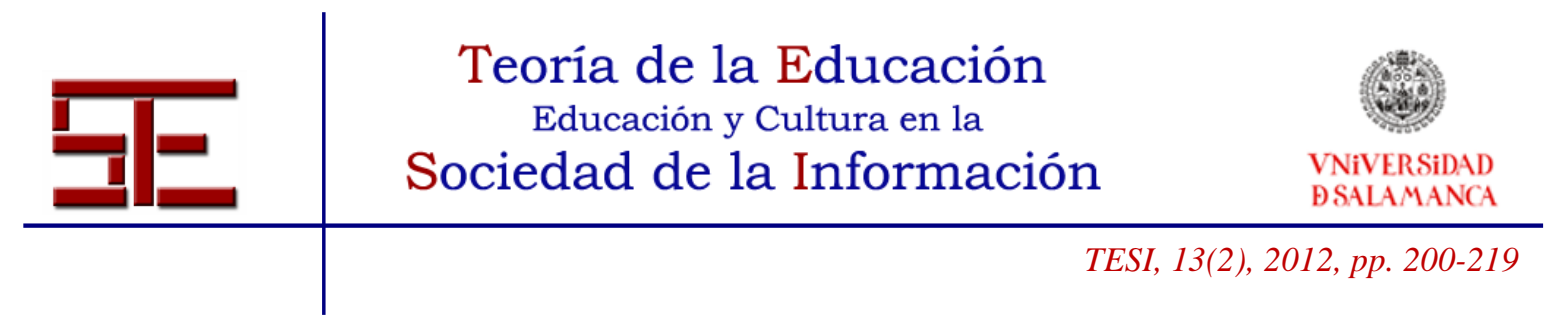

c y d) Por lo que respecta a la responsabilidad individual y personal y al uso de habilidades interpersonales en grupos pequeños, apenas requiere mención dada la composición voluntaria (y cabe añadir entusiasta) del equipo y su amplia experiencia en entornos cooperativos, tanto presenciales como virtuales.

e) El procesamiento grupal, definido por Johnson y Johnson (op. cit. 129) como "la reflexión sobre una actividad grupal para ver qué acciones de sus integrantes resultaron útiles y cuáles no lo fueron y para tomar decisiones sobre qué acciones se deben conservar y cuáles se deben cambiar", ha supuesto un reto singular en el diseño metodológico. La diversidad de motivaciones y actitudes derivada de la heterogeneidad del grupo, el diferente grado de disponibilidad, la inercia de ciertas atribuciones a los roles de profesor y alumno (amén de sus dispares compromisos académicos), la dispersión geográfica y el privilegio del trabajo asincrónico confieren una enorme importancia a las tareas de coordinación.

\subsection{Producción entre iguales basada en el procomún}

Aunque las pautas del aprendizaje cooperativo presentan múltiples similitudes con lo descrito respecto de la producción entre iguales basada en el procomún, es importante considerar qué aportaciones específicas de esta hemos adoptado en nuestro proyecto.

Como se exponía previamente, un primer aspecto que tener en cuenta es la disponibilidad tanto de la "maquinaría física" requerida para almacenar y conectar nuestra producción como de "las materias primas fundamentales". En este punto proyectos como el nuestro se benefician de que dicha disponibilidad en gran medida viene dada de antemano. Con respecto a la maquinaria física, contábamos con los ordenadores, conexiones de Internet y dispositivos de almacenamiento domésticos, además de con los que nos proporcionaban nuestros respectivos centros de trabajo. En cuanto a la materia prima informativa, nuestra iniciativa se beneficiaba de la misma autorización previa que nos daba Lessig para trabajar con sus libros: Yochai Benkler también publicó su obra con una licencia $\mathrm{CC}$ que nos invitaba a realizar obras derivadas no comerciales sin necesidad de permiso o desembolso. De este modo, el diseño de nuestro proyecto cumplía el requisito primordial de las modalidades productivas en la economía de la información en red: “... que todos los insumos necesarios para la actividad productiva efectiva estén bajo el control de los usuarios individuales" (Benkler, 107).

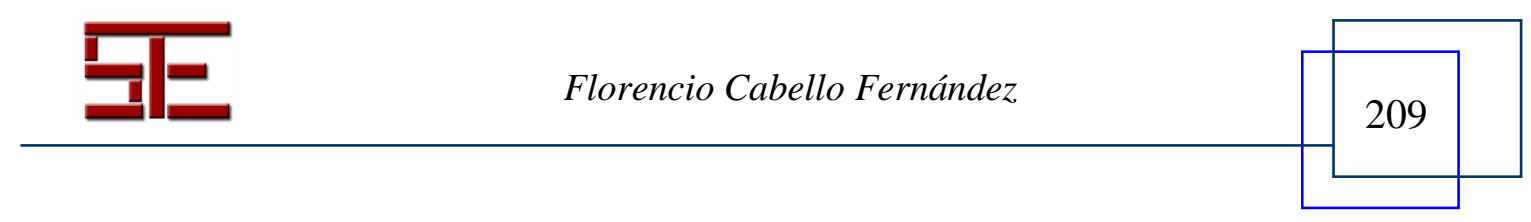




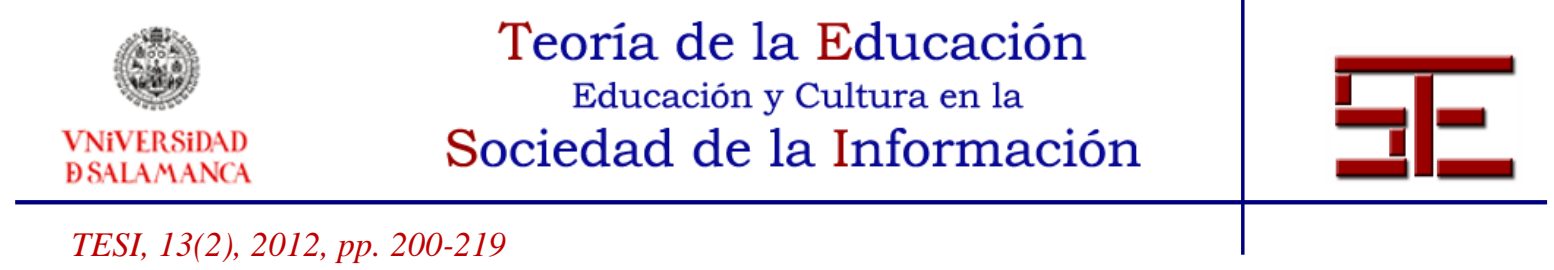

Por lo que concierne a nuestro diseño de una arquitectura técnica y organizativa que propiciara la integración de aportaciones muy diversas, tratamos de ajustar tanto su modularidad como su granularidad a la naturaleza específica de nuestra tarea. Así, en nuestro caso la división en módulos se correspondía sencillamente con la estructura de capítulos de la obra. Dichos capítulos se colgaron en su versión original en nuestra plataforma virtual (que describiremos a continuación) y se fueron asignando para su traducción por los colaboradores en función de sus preferencias y disponibilidad y siempre bajo la supervisión general de los coordinadores.

En este punto nuestro diseño metodológico tuvo que asumir una dificultad que Benkler pone de relieve en su obra: los proyectos relacionados con la producción textual requieren una inversión mínima de tiempo y esfuerzo medianamente considerable para dotar de coherencia al trabajo sobre el módulo escogido y ensamblarlo con los demás. Esta granularidad relativamente gruesa de las contribuciones mínimas se verificaba en nuestro caso, pero intentamos mitigarla descomponiendo por epígrafes coherentes los grandes módulos iniciales correspondientes a los capítulos 6, 7, 10 y 11 con el fin de animar a algunos colaboradores a encargarse de ellos de forma conjunta. De este modo, pese a que Benkler afirma que la producción entre iguales basada en el procomún requiere el predominio del grano fino, asumimos que la heterogeneidad de colaboradores (y de sus respectivas motivación y disponibilidad) debía reflejarse en la diversidad de la granularidad de los módulos, en nuestro caso predominantemente gruesa.

Junto a estas dos consideraciones fundamentales, hay una tercera decisión metodológica directamente inspirada por la concepción tecnológica expuesta en el punto anterior: la apuesta por el empleo de software libre. Y es que, pese a que buena parte de las investigaciones sobre el empleo didáctico de las TIC insisten en la necesidad de garantizar su calidad pedagógica mediante el protagonismo de los profesores en la colaboración con los tecnólogos, e incluso subrayan que su viabilidad se ve amenazada por la obsolescencia (Rodríguez Izquierdo, 2010; 44), no son tantas las que vinculan esas cuestiones con la opción fundamental entre arquitecturas técnicas abiertas (software libre y estándares — formatos, lenguajes... - abiertos) y cerradas (software privativo y estándares cerrados).

Antes de exponer nuestra opción concreta por las arquitecturas abiertas, precisaré brevemente qué significa el software libre. Para ello es ineludible citar a Richard

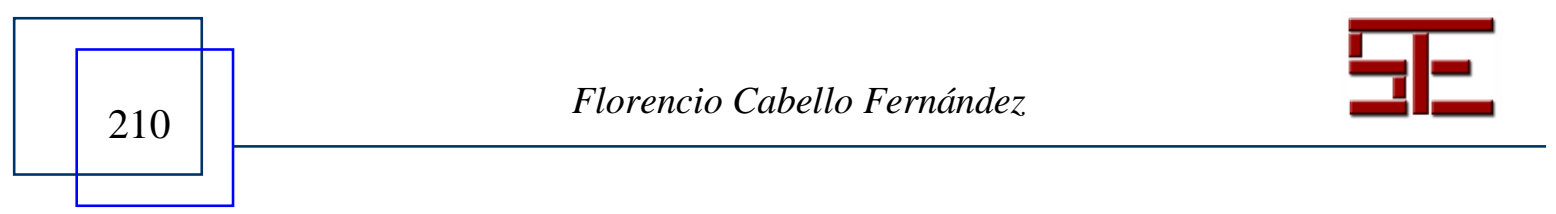




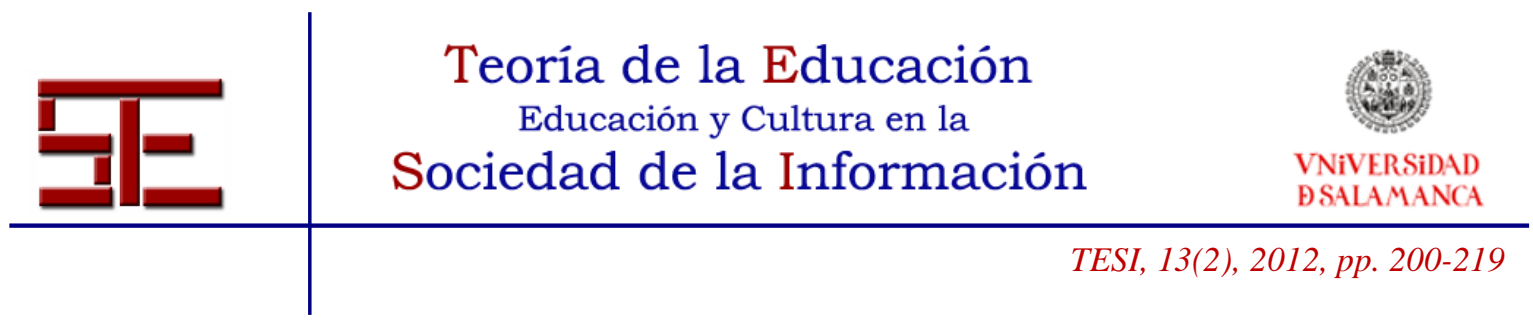

Stallman, hilo conductor entre el actual movimiento de software libre y la cultura hacker que se gestó en EE.UU a partir de los 60 en torno a los laboratorios de investigación universitarios y los clubs de hobbyists informáticos que modelaron la actual Internet (Cabello, 2007; 208-234). Pues bien, Stallman (2004; 59-60) define el software libre a partir de las cuatro libertades básicas que respeta y promueve:

*Libertad 0: la libertad para ejecutar el programa sea cual sea nuestro propósito.

*Libertad 1: la libertad para estudiar el funcionamiento del programa y adaptarlo a tus necesidades -el acceso al código fuente es condición indispensable para esto.

*Libertad 2: la libertad para redistribuir copias y así ayudar a tu vecino.

*Libertad 3: la libertad para mejorar el programa y luego publicarlo para el bien de toda la comunidad -el acceso al código fuente es indispensable para esto.

Partiendo de este componente ético, Stallman (2003) especifica cuatro motivos para adoptar el software libre en el ámbito educativo:

a) Ahorro económico. El motivo más superficial, y obvio, derivado de la libertad de copia.

b) Rechazo a "enseñar dependencia" de programas privativos que propician abusos por parte de las grandes corporaciones informáticas.

c) Rechazo del "sacerdocio de la tecnología", que inmoviliza a la gente en la ignorancia del funcionamiento de la tecnología" (idem). Con el software libre, los estudiantes pueden estudiar el código fuente y modificarlo a su antojo (sin ir más lejos, pueden traducirlo a su propia lengua).

d) Educación moral: Coherencia con la misión social de la escuela de formar "ciudadanos de una sociedad libre, capaz, independiente y de cooperación", lo cual, "en el ámbito informático se traduce en enseñar a compartir el software" (idem).

Fundamentados en este y otros trabajos en esta línea (Valverde, 2007), recurrimos a la recién liberada aplicación Etherpad ${ }^{1}$ para construir un espacio educativo virtual que proporcionaría todas las funcionalidades del wiki para la edición textual cooperativa y descentralizada, pero añadiendo dos importantes ventajas: Etherpad habilita que varias personas trabajen simultáneamente sobre un mismo documento e incorpora un chat para coordinarse en tiempo real. Junto a ello, la posibilidad de resaltar las aportaciones de cada colaborador asignándole un color de letra particular prometía facilitar el

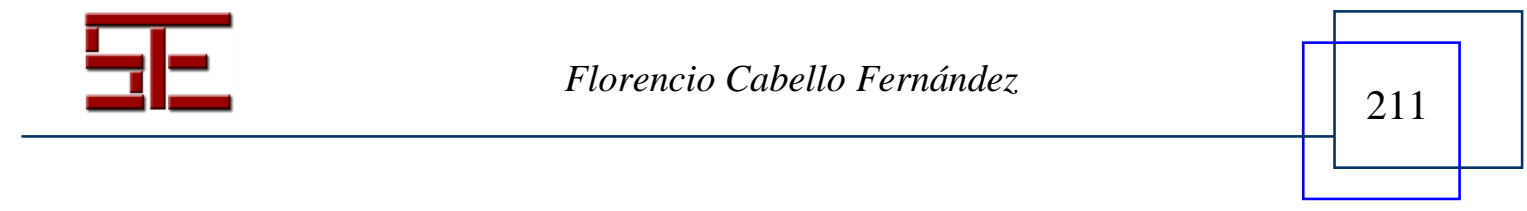




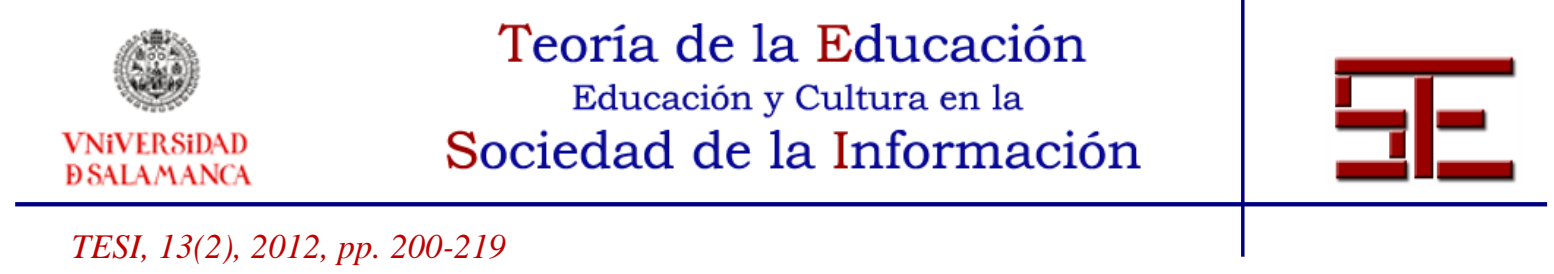

seguimiento personalizado y permanente del trabajo por parte de los coordinadores ${ }^{2}$. Finalmente, el diseño de nuestra plataforma cooperativa virtual no ignoró la importancia de asegurarnos el control de la "maquinaria física" y la información frente a la tentación de recurrir a servicios comerciales en la nube con los que cedemos dicho control en manos corporativas. Para ello contamos con la pericia de Gabriel Lucas, técnico de Medialab-Prado que alojó nuestra plataforma Etherpad en un servidor propio donde nuestra traducción en línea estaría a buen recaudo.

\section{RESULTADOS}

Expuesto todo lo anterior, se reseñan a continuación los principales logros del proyecto con el fin de aportar elementos de juicio que sustenten la reflexión educativa sobre trabajo cooperativo, TIC y producción social.

En primer lugar, cabe destacar que el "grupo cooperativo de base" que durante 2010 colaboró en la traducción y edición en castellano de The Wealth of Networks ha logrado reunir a dieciséis personas de distintas procedencias: para empezar, las tareas de coordinación docente pasaron a ser compartidas entre Florencio Cabello y Andoni Alonso, profesor de Filosofía de la UCM; en cuanto a los estudiantes, a los tres alumnos de la UMA que cursaban Tecnología de la Comunicación Audiovisual en el curso 2009/2010 (Ana Arjona, José Antonio Villalobos y Beatriz Gómez) se sumaron seis antiguos alumnos de la misma materia (Maryam Itatí Portillo, Carola Felis, Laura Vacas, Nikita Bachmakov, Lutfi Zetón y María García) y un estudiante (Marcos Pérez) de la Escuela de Organización Industrial de Madrid (EOI); más allá, tanto estudiantes como profesores pudimos enriquecer nuestra colaboración con la participación de profesionales no académicos vinculados con el foco de estudio (Frédérique Muscinesi, responsable de eventos de la EOI, y Marcos García, responsable de programación del Medialab-Prado) o con la propia traducción profesional (Giulia Faraguna). Junto a ello, la convocatoria paralela de un grupo de lectura que, en el marco de las actividades de la Casa Invisible de Málaga en 2010, revisaba la obra a medida que se traducía, permitió la incorporación de la ambientóloga Violeta Cabello, estudiosa del "procomún tradicional" de los recursos naturales. Finalmente la integración de este grupo heterogéneo en el conjunto de proyectos del LdP nos permitió contar con el asesoramiento de académicos y profesionales de diversos campos, entre los que destacó el papel del historiador de la ciencia Antonio Lafuente y del abogado Javier de la Cueva.

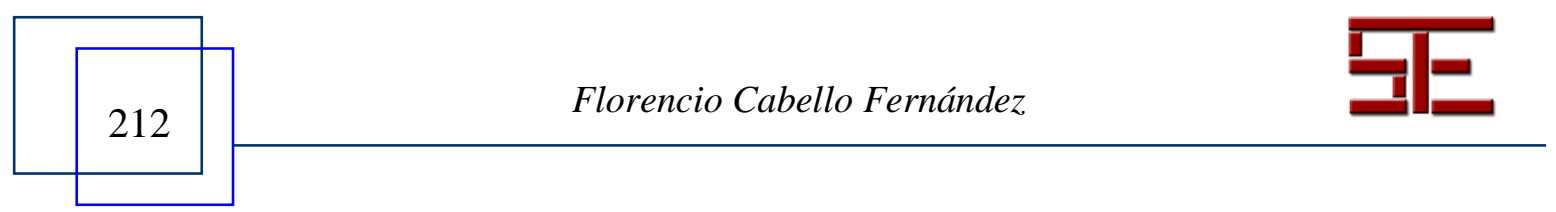




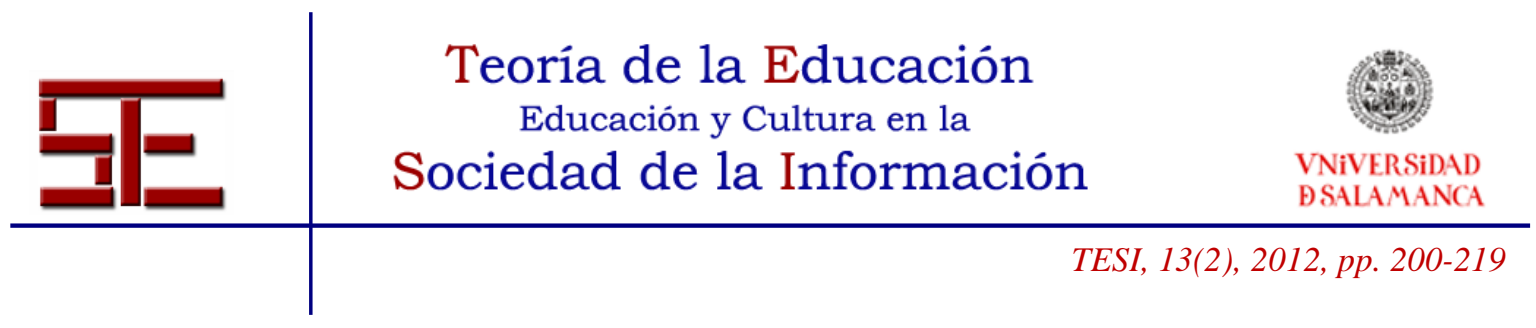

Por lo que respecta al proceso de aprendizaje cooperativo, la heterogeneidad del equipo aconsejó basar la interdependencia positiva de objetivos en la producción de una obra concreta: la traducción del libro en sí. Este objetivo común llevaba aparejadas diversas recompensas complementarias para cada uno de los componentes, entre las que las calificaciones de los estudiantes de la UMA o de la EOI acabaron verificándose como secundarias. No en vano, todos ellos siguieron colaborando una vez superadas las materias relacionadas con el proyecto en la convocatoria de junio de 2010.

Esta interdependencia positiva se complementó con el reconocimiento de la labor del equipo de distintas formas: la primera, ya explicada, mediante la evaluación académica de los estudiantes de la UMA; la segunda, fundamental, a través de las reuniones de coordinación bimensuales que, en el marco del LdP, propiciaban un espacio híbrido entre academia e institución cultural donde universitarios, profesionales y participantes en movimientos sociales nos interesábamos por nuestros respectivos avances; la tercera provenía del grupo de lectura paralelo a la traducción que nos permitía recabar correcciones y sugerencias a la vez que traducíamos; y, por último, lo más parecido al "festejo" conjunto del éxito que subrayan Johnson y Johnson fue la celebración en Medialab-Prado a finales de junio de 2010 de un seminario con la participación del propio Yochai Benkler. Además de la riqueza de la documentación emanada del registro audiovisual de los tres días que duró el seminario ${ }^{3}$, para todo el equipo resultó sumamente gratificante que el autor de la obra que estudiábamos acudiera expresamente desde Harvard a conocer de primera mano nuestra experiencia.

Por otra parte, no es de extrañar el singular valor atribuido a estos intensos momentos de "interacción promotora cara a cara" si recordamos lo señalado previamente acerca de la predominancia de la dimensión virtual en la coordinación del trabajo de "individuos extensamente distribuidos y difusamente conectados". En este marco adquiere plena relevancia la introducción de las TIC para la configuración de espacios virtuales educativos que canalicen "la capacidad de trabajo en red", posibilitando "una localización geográficamente dispersa de los participantes y un sincronismo o un asincronismo de las actividades formativas, según sea necesario" (García Peñalvo y García Carrasco, 2002). En este sentido, baste apuntar como ejemplos que la disposición en la plataforma virtual descrita en el epígrafe 3.2 de páginas de discusión para cada capítulo y de un glosario que todos podían consultar y completar permitía mantener la homogeneidad y canalizar las aportaciones sin necesidad de verse las caras cotidianamente.

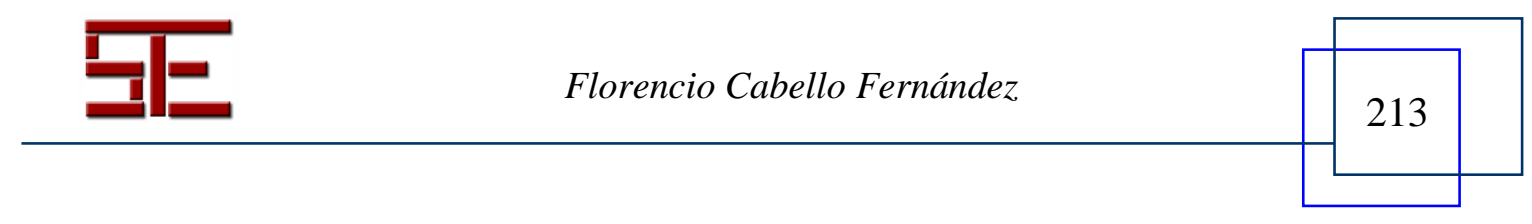




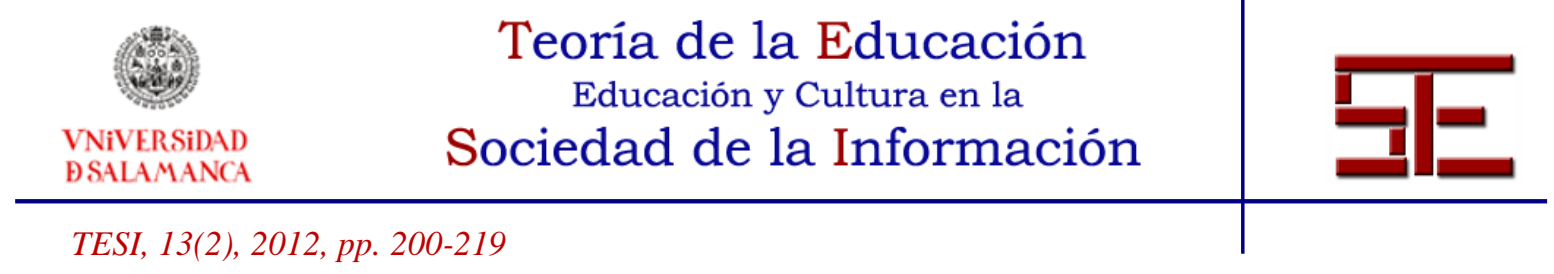

Otro aspecto reseñable observado en el transcurso del proyecto, y que atribuimos a la creciente implantación de metodologías de aprendizaje cooperativo en la educación superior, es que los estudiantes han demostrado una notable destreza en el trabajo en equipo basado en TIC. De este modo, una vez que los docentes esbozamos la metodología de cooperación básica y diseñamos la plataforma virtual acorde con ella, los estudiantes se apropiaron de ella rápidamente e incluso nos ofrecieron sugerencias valiosas para su mejora. Por último, estimamos interesante ofrecer un breve apunte sobre el sempiterno problema del polizón que amenaza las iniciativas cooperativas. En nuestro caso, la posibilidad que brinda Etherpad de marcar las aportaciones de cada voluntario con un color distintivo facilitó que cualquiera realizara un seguimiento permanente de los avances de los demás para reconocerles su labor y regular la suya propia.

Junto a los encuentros presenciales mencionados y a la posibilidad de seguimiento virtual permanente, otro aspecto crucial para el "procesamiento grupal" de la experiencia ha sido el esfuerzo de los coordinadores por acompañar el proceso de edición con citas (necesariamente individuales o en pequeños grupos, preferentemente presenciales pero también virtuales) para discutir la versión final con los colaboradores y recoger sus valoraciones. Como colofón de todo ello, el arquitecto de nuestro espacio virtual educativo, Gabriel Lucas, habilitó a través del mismo espacio una consulta colectiva para recabar sugerencias de mejora del software Etherpad.

Además de estas valoraciones sobre el desarrollo del proceso de aprendizaje cooperativo, resulta imprescindible reseñar algunos de los frutos concretos que ha dado este proyecto. Empezando por la dimensión más reconocible académicamente, la culminación de la versión inicial de la traducción a finales de 2010 dio pie a un proceso final de revisión por parte de los coordinadores que ha desembocado en la disponibilidad de una traducción completa de The Wealth of Networks cuya publicación está prevista para la segunda mitad de 2012. Con ella serán tres las publicaciones surgidas de los proyectos de traducción cooperativa que comenzaron en la UMA en 2008, una vez que ya han aparecido en castellano nuestras dos traducciones de Lessig (2009 y 2012).

Desde una óptica más centrada en aspectos docentes, la repercusión de estas publicaciones también es significativa. Por lo que se refiere al legado que cada promoción deja a las siguientes, hay que subrayar que, al igual que sucede con las obras de Lessig empleadas en la asignatura Tecnología de la Comunicación Audiovisual, en el

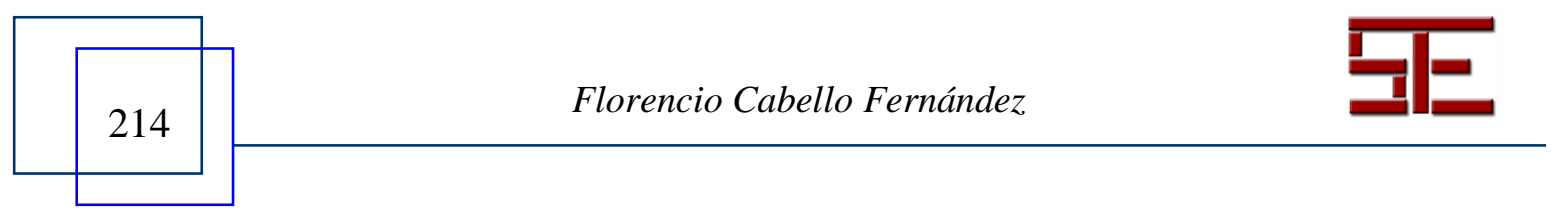




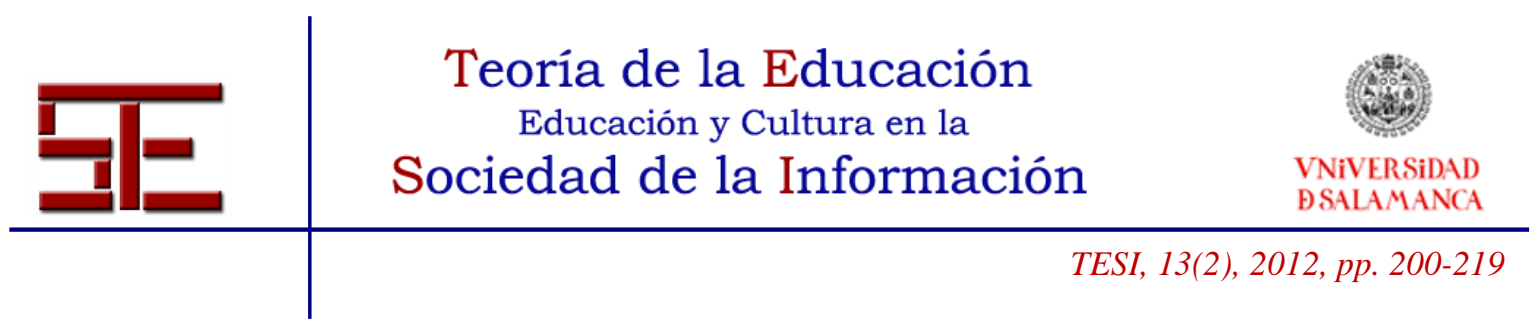

curso 2011/2012 nuestra versión inédita de la obra de Benkler ya se ha incorporado como material didáctico de una segunda asignatura de nueva implantación en la UMA: Tecnologías Aplicadas a la Publicidad y las Relaciones Públicas.

Del mismo modo, la dinámica iniciada en 2008 con El Código 2.0 por la que los propios estudiantes presentaban el proyecto en distintos foros ${ }^{4}$ ha tenido continuidad con otras dos intervenciones públicas en 2011 y $2012^{5}$. Más allá de las obvias implicaciones relativas a la competencias de trabajo cooperativo o de comprensión escrita en lengua extranjera, uno de los logros más gratificantes del proyecto ha sido que el protagonismo que los estudiantes han asumido en la producción de su material didáctico ha tenido un fiel reflejo en su solvencia a la hora de exponer públicamente las claves del proyecto.

Para finalizar, reseñamos brevemente el último fruto de nuestro proyecto: el lanzamiento en 2012 del blog http://traduccionesprocomun.org, donde se recaba información vinculada al proyecto. Antes de pasar a las Conclusiones de este artículo, me permito destacar dos secciones en particular de este sitio web: la primera es "Nuestra receta", que incluye una explicación sintética de nuestra metodología de trabajo a través de una sugerente analogía culinaria; la segunda es "Archivo", donde entre otras cosas puede comprobarse que el legado de nuestro proyecto ha dejado de ceñirse al ámbito de la docencia de la UMA. En efecto, respecto de nuestra primera traducción publicada, la de El Código 2.0, el blog deja constancia de su empleo como material didáctico en distintas universidades de España, Argentina, Chile y México. He aquí una buena ilustración de la idea que abría este texto: la de la potencia que supone la afluencia de la "riqueza de las redes" a la educación universitaria.

\section{CONCLUSIONES}

Mi valoración de la combinación de aprendizaje cooperativo y producción entre iguales basada en el procomún en que se basa este proyecto parte de la constatación del mutuo enriquecimiento que se deriva de la heterogeneidad de los equipos. Sin olvidar la vinculación con una asignatura y unos estudiantes concretos que participan en la construcción del material didáctico que legarán a sus compañeros, la apertura a colaboradores externos refuerza la interdependencia positiva mediante el conocimiento y reconocimiento mutuos entre estudiantes, profesores y profesionales. Así, incluso si la actividad de los alumnos comporta un innegable desajuste en términos de evaluación formal por exceder los límites espacio-temporales de la materia en cuestión, ello también facilita la labor docente ya que "el proceso de evaluación se hace en realidad

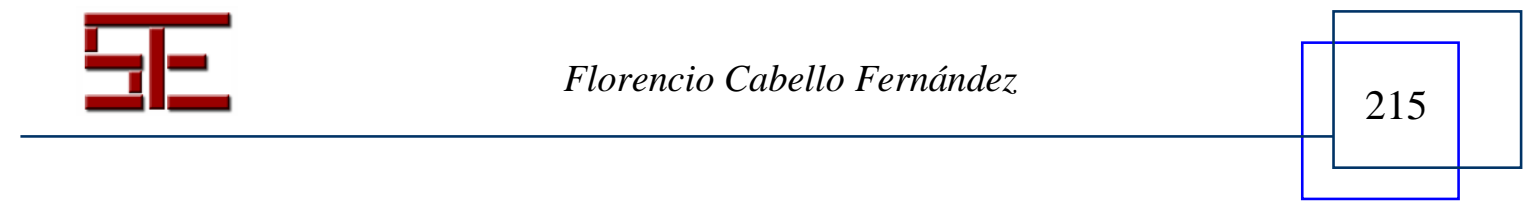




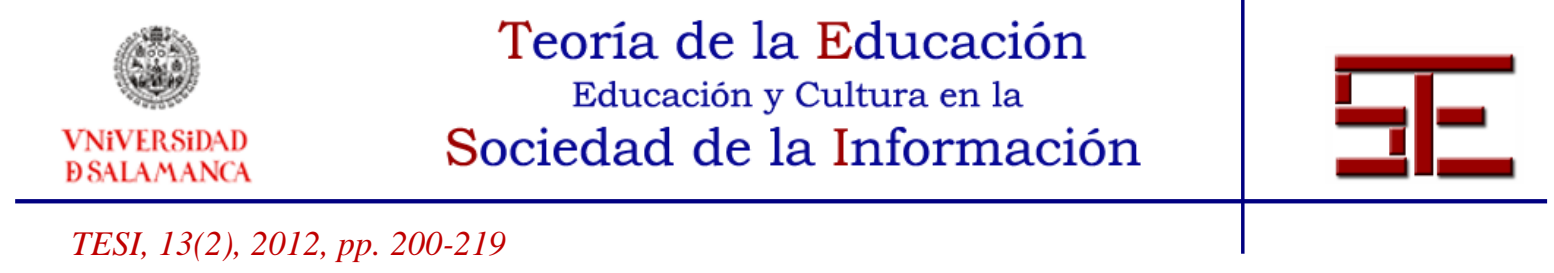

más transparente y objetivo al introducir objetivos que pueden ser evaluados externamente" (Freire, 2009: 3). En este sentido, la integración del proyecto en el LdP y la culminación del debate con Benkler han sido excepcionalmente fructíferas.

Obviamente esto entraña una profunda redefinición de los roles de profesor y alumno. Así, mientras que los estudiantes "deben actuar cada vez más como socios y pares del profesor en la construcción de conocimiento como una estrategia de aprendizaje", los profesores hemos de asumir "papeles de consultores y facilitadores de información, facilitadores del aprendizaje, diseñadores de medios, moderadores y tutores virtuales y/o presenciales, orientadores, y evaluadores continuos" (idem). Ahora bien, ello exige un arduo encaje de bolillos con los respectivos compromisos académicos ( $\sin$ ir más lejos, el seminario con Benkler coincidió con los exámenes de junio) y, sobre todo, una importante dedicación que choca con criterios de evaluación académica que ignoran, cuando no penalizan, estos procesos cooperativos.

Esto nos remite a dos cuestiones vinculadas con la producción entre iguales basada en el procomún. La primera es la importancia de diversificar la granularidad de los módulos, de modo que, junto a contribuciones amplias por capítulos, quepan otras más reducidas por epígrafes. El riesgo que para el aprendizaje del estudiante podría suponer la consiguiente pérdida de perspectiva general de la obra se compensa mediante su asistencia a las revisiones y sesiones de discusión presenciales. La segunda atañe al éxodo del Campus Virtual de la UMA donde trabajábamos este proyecto. Esto se justifica porque su arquitectura, pese a ofrecer estar basada en la aplicación libre Moodle y ofrecer una herramienta de trabajo descentralizado como el wiki, otorga al profesor un control centralizado que dificulta la apertura a colaboradores externos y la redefinición de roles académicos.

Por contra, la instalación de Etherpad en un servidor propio, aun conllevando un ligero retraso en el inicio del trabajo por su complejidad, ha proporcionado un acceso inmediato, pleno e igualitario a todos los participantes, con una simple identificación por colores y sin entrañar problemas de modificaciones malintencionadas. Más aún, esta decisión ha estimulado la incipiente conversión de los colaboradores en un "público recursivo" (Kelty, 2008), esto es, en usuarios activamente comprometidos con el mantenimiento de nuestra plataforma de cooperación virtual. De este modo, hemos podido recabar sugerencias de mejora de Etherpad (relativas, entre otras, a las limitaciones de la caja de texto y a la importación y exportación de documentos) destinadas a su equipo de desarrolladores, algo que difícilmente sucedería en el contexto

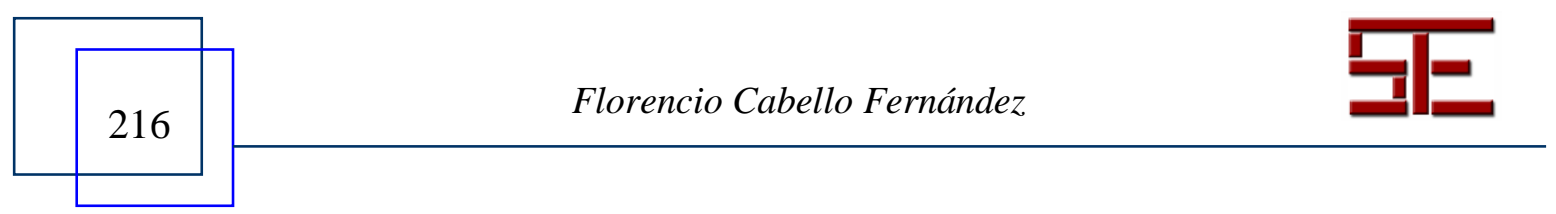




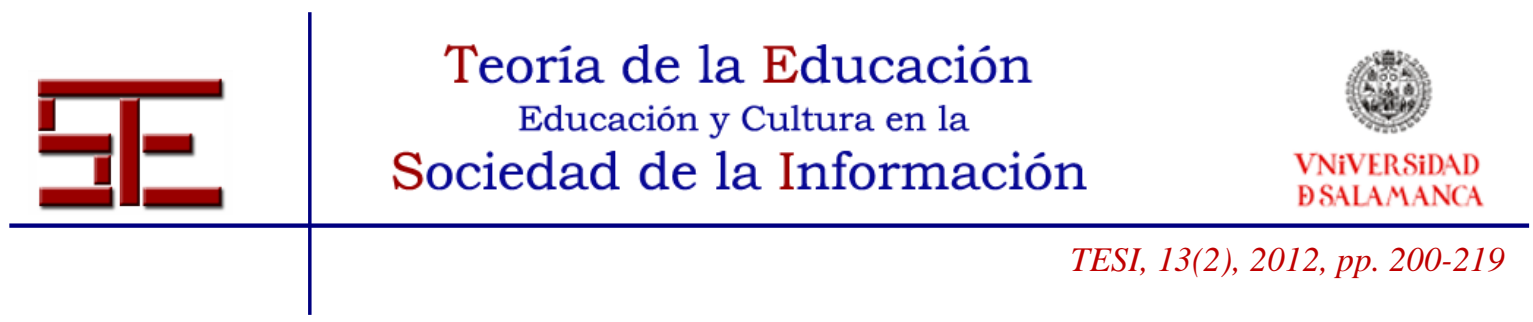

del Campus Virtual por entrañar un desafío de fondo a sus principios panópticos. Huelga añadir que la contrapartida de este éxodo es justamente la invisibilidad a ojos de muchos de los Vicerrectorados encargados de certificar las actividades virtuales.

Para concluir, deseo acentuar que el proyecto de traducción de The Wealth of Networks me ha reafirmado en el convencimiento de la viabilidad de iniciativas académicas que combinen coherentemente la investigación sobre la producción entre iguales basada en el procomún con el despliegue de metodologías de aprendizaje cooperativo a caballo entre lo presencial y lo virtual. No en vano, a lo largo de este texto se evidencia que el estudio de la obra de Benkler ha proporcionado fundamentos teóricos para afinar un proceso de enseñanza/aprendizaje que, a su vez, los actualiza y contrasta en la práctica, amén de divulgarlos ulteriormente con la producción de una obra derivada. En definitiva, se trata de indagar la producción social experimentándola, y de experimentarla a través de su indagación. Creo que a eso se refería Yochai Benkler cuando, tras visitar nuestro espacio virtual, nos felicitó afirmando: "Observar la colaboración en la traducción es observar el proceso contando su propia historia".

\section{6.- BIBLIOGRAFÍA}

Benkler, Y. (2006). The Wealth of Networks. How Social Production Transforms Markets and Freedoms. New Haven: Yale University Press.

Cabello, F. (2004). Algunos derechos reservados: Creative Commons y propiedad intelectual. Babab.com. 25. Extraído el 21 de mayo, 2012, de http://www.babab.com/no25/creative_commons.php.

Cabello, F. (2007). Distorsión comunicativa: Aproximación a los modos de consumir a través de las industrias culturales en red. Málaga: Spicum.

- (2009). Introducción. En L. Lessig, El Código 2.0 (trad. por Maryam Itati Portillo et al.) (pp. 15-19). Madrid: Traficantes de Sueños.

Freire, J. (2009). Presentación. En J. Freire. (Coord.), Cultura digital y prácticas creativas en educación [monográfico en línea]. Revista Universidad y Sociedad del Conocimiento vol. 6, 1, 2-6. UOC. Extraído el 21 de mayo, 2012, de http://www.uoc.edu/ojs/index.php/rusc/article/view/23/16

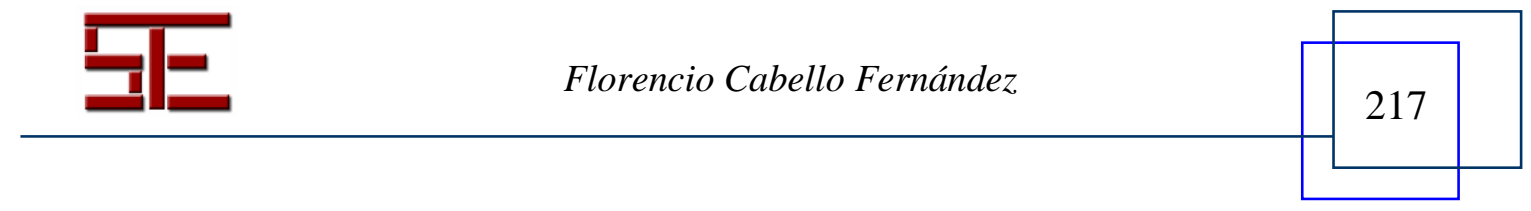




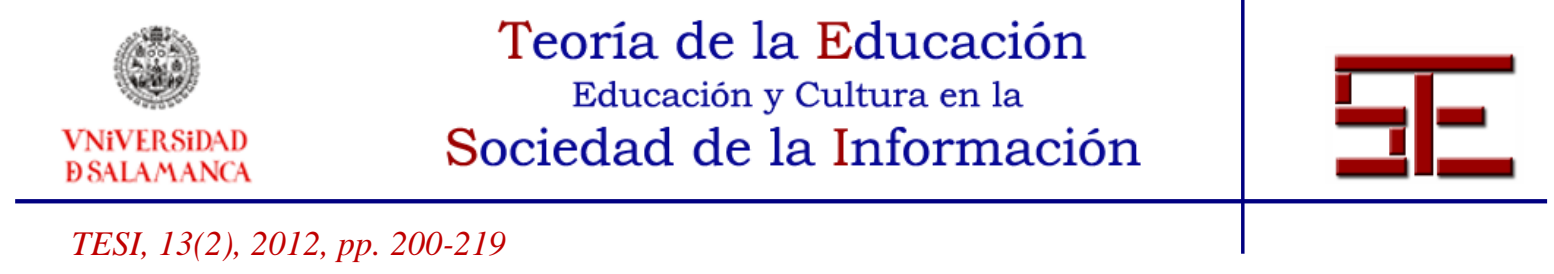

García Peñalvo, F. J. y García Carrasco, J. (2002). Los espacios virtuales educativos en el ámbito de Internet: un refuerzo a la formación tradicional. Revista Electrónica Teoría de la Educación: Educación y Cultura en la Sociedad de la Información, 3. Extraído el 21 de mayo, 2012, de

http://campus.usal.es/ teoriaeducacion/rev_numero_03/n3_art_garcia-garcia.htm

Hess, C. \& Ostrom, E. (Eds.) (2007). Understanding Knowledge as a Commons. From Theory to Practice. Cambridge: The MIT Press.

Johnson, D. W. \& Johnson, R. T. (1999). Aprender juntos y solos: Aprendizaje cooperativo, competitivo e individualista (trad. por Miguel Wald). Buenos Aires: Aique.

Kelty, C. (2008). Two Bits. The Cultural Significance of Free Software. Durham: Duke University Press.

Lessig, L. (2008). Remix. Making Art and Commerce thrive in the Hybrid Economy. Nueva York: Penguin.

- (2009). El Código 2.0 (trad. por Maryam Itati Portillo et al.). Madrid: Traficantes de Sueños.

- (2012). Remix (trad. por Maryam Itati Portillo et al.). Barcelona: Icaria.

Rodríguez Izquierdo, R. M. (2010). El impacto de las TIC en la transformación de la enseñanza universitaria: repensar los modelos de enseñanza y aprendizaje. En De Pablos Pons, J. (Coord.). Buenas prácticas de enseñanza con TIC [monográfico en línea]. Revista Electrónica Teoría de la Educación: Educación y Cultura en la Sociedad de la Información, vol. 11, 1 32-68. Universidad de Salamanca. Extraído el 21 de mayo, 2012, de http://revistatesi.usal.es/ revistas_trabajo/index.php/revistatesi/article/view/ http://campus.usal.es/ revistas_trabajo/index.php/revistatesi/article/view/5788/5818 Rodríguez.

Stallman, R. (2003). Por qué las escuelas deberían usar exclusivamente software libre. Extraído el 21 de mayo, 2012, de http://www.gnu.org/philosophy/schools.es.html

- (2004). Software libre para una sociedad libre (trad. por Jaron Rowan, Diego Sanz Paratcha y Laura Trinidad). Madrid: Traficantes de Sueños.

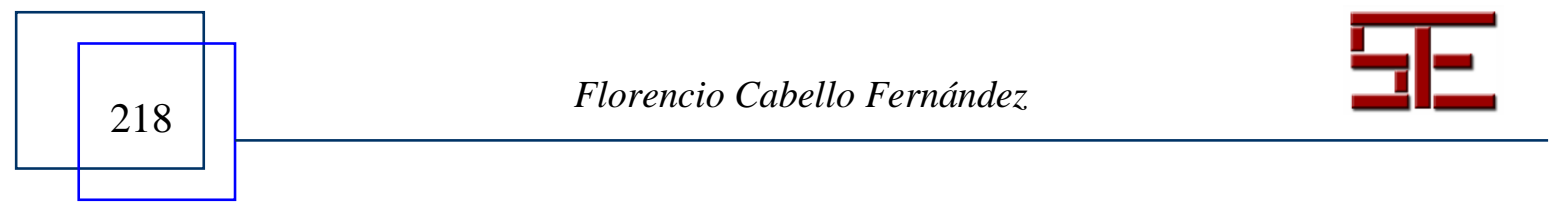




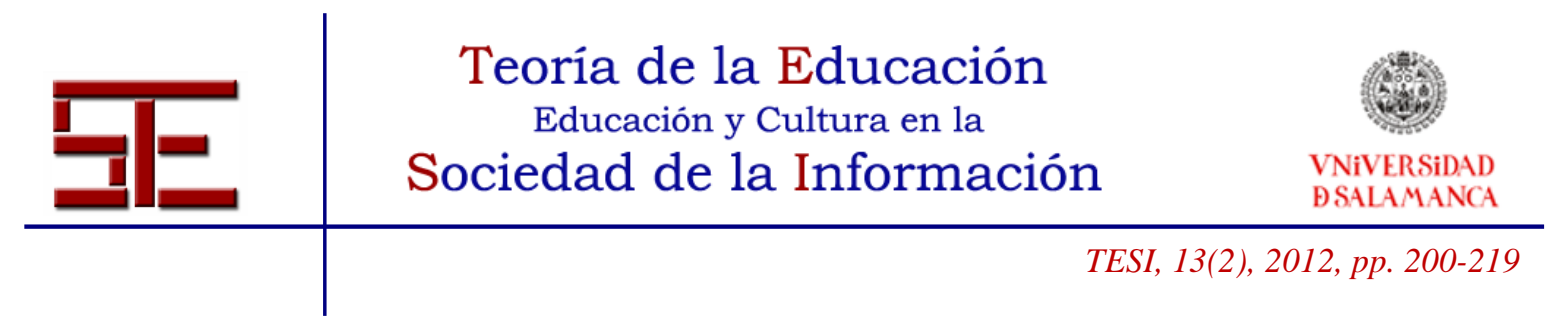

Valverde Berrocoso, J. (2007). El software libre y las buenas prácticas educativas con TIC. Comunicación y Pedagogía, n.o 222, 48-55.

Winner, L. (2008). ¿Tienen política los artefactos?. En La ballena y el reactor: una búsqueda de los límites en la era de la alta tecnología (ed. por Javier Bustamante) (pp. 55-81). Madrid: Gedisa.

\section{7.- NOTAS}

1. Agradezco a Marga Padilla y Ana Méndez su sugerencia en este sentido.

2. Véase: http://traduccionesprocomun.medialab-prado.es/.

3.Véase:

http://medialab-

prado.es/article/discusion_sobre_parte_dos_la_economia_politica_de_la_propiedad_y_el_procomun_1.

4.Véanse:

http://www.opensourceworldconference.com/oswc/programme/media/view_media?dia=21\&idtitulo=dia_ 2_sala_6_1200-1400_sesion_cientifica_traduccion_codigo_2 (presentación en el Congreso Internacional de Software Libre de Málaga el 21 de octubre de 2008) y http://medialabprado.es/article/la_arquitectura_del_ciberespacio (presentación en el Medialab-Prado el 20 de mayo de 2009).

5. Véanse: http://medialab-prado.es/article/reunion_general_procomun_10_feb_2011 (presentación en el Laboratorio del Procomún el 10 de febrero de 2011) y http://medialabprado.es/article/mesa_2_aprender_haciendo_conocimiento_y_aprendizaje_en_comunidad_(presentación en Laboratorios de Internet el 1 de marzo de 2012).

Para citar el presente artículo puede utilizar la siguiente referencia:

Cabello Fernández, F. (2012). La riqueza de las redes en la educación universitaria: "Traducción entre iguales basada en el procomún" de The Wealth of Networks. Revista Teoría de la Educación: Educación y Cultura en la Sociedad de la Información. 13(2), 200-219 [Fecha de consulta: dd/mm/aaaa].

http://campus.usal.es/ revistas_trabajo/index.php/revistatesi/article/view/9005/9250

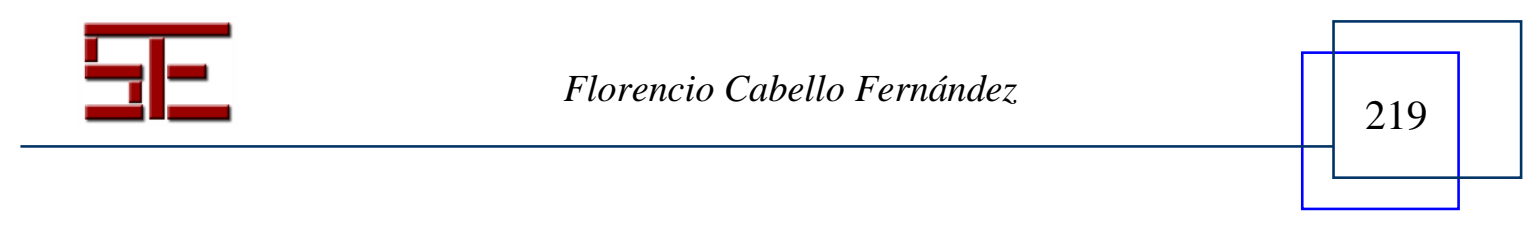

